\title{
MAKING CONTRIBUTIONS FROM INTERPRETIVE CASE STUDIES: Examining Processes of Construction and Use
}

\author{
Michael Barrett \\ Geoff Walsham \\ Judge Institute of Management \\ University of Cambridge
}

\begin{abstract}
In this paper, we examine how contributions are established in interpretive case studies. By focusing on the introductory sections of articles, previous research in the organizational literature has recently shed light on how theorists construct opportunities for making contributions. Our theoretical approach is broader in scope, examining both the construction and use of contributions in all sections of an article. We use this approach to explore how a well-ited IS interpretive case study makes contributions. With respect to constructing contributions, our findings confirm previous strategies suggested by earlier research, and uncover the use of plural strategies. Our analysis of the use of contributions is more unexpected. For example, key theoretical and conceptual contributions that were central to the case study were rarely drawn on and incorporated by later texts. Rather, multiple audiences took up the softer, and simpler, conceptual contributions. Furthermore, our findings categorize a number of different types of referencing used by later texts in incorporating and using contributions, namely mistaken referencing, ambiguous referencing, incorporating into a new term, and related work referencing. We conclude by providing some suggestions as to how IS researchers can make better contributions from interpretive case studies
\end{abstract}

Keywords: Contributions, construction use, interpretive case studies, research methods, evaluation 


\section{INTRODUCTION}

\subsection{What Is a Contribution?}

Whether one is a doctoral student preparing his or her thesis or an experienced researcher responding to reviewers' comments, the question "what is a contribution?" continues to be a challenge in written work. A key debate in the IS literature has been on the relevance of our research (Benbasat and Zmud 1999; Davenport and Markus 1999). An equally important dimension of knowledge construction in establishing a contribution has been evident in recent IS research. For example, March and Smith (1995) provided an evaluative framework for both design and natural science research in IT research. More recently, Webster and Watson (2002) provide guidance on constructing and articulating a review paper's contribution, while Klein and Myers (1999) offer a set of principles for conducting and evaluating IS interpretive field studies. This latter focus on the quality of contributions in interpretive work (Klein and Myers 1999) is perhaps not unexpected given the emergence of interpretive research (Walsham 1995a) in IS and its significant development over the last decade. In this paper, we seek to build on the current literature by carrying out needed empirical work to understand both how interpretive case studies develop contributions in their texts (cf. Locke and Golden-Biddle 1997) and to examine the subsequent use of these contributions in later texts.

Research in the organizational literature on the importance of contribution in scientific work has tended to focus on novelty or uniqueness as a key aspect of what constitutes contribution (Astley 1985; Locke and Golden-Biddle 1997). Reviewers often ask what's new or innovative about a work (Weick 1995; Whetten 1989) and scholars are urged to make unique contributions to their discipline (Mone and McKinley 1993). Furthermore, there is growing evidence of the link between novelty and uniqueness, and publication in journals (Beyer et al. 1995).

Locke and Golden-Biddle's (1997) pathbreaking work shifts this focus on the importance of contribution to examining what contribution means in practice. Their approach views contribution as the socially constructed nature of scientific knowledge (Knorr-Cetina 1981; Latour 1987), which has two key premises: (1) knowledge cannot be known separately from the "knower" and (2) knowledge is a meaning-making activity "enacted" in particular communities (Orlikowski and Baroudi 1991). This perspective suggests that knowledge is not an objective entity independent of the knower in a world composed of facts. As elaborated in the next section, their empirical work is valuable in highlighting two key processes upon which texts draw in constructing opportunities for contribution. However, as they themselves note, their grounded theory study on the how of contribution is somewhat limited in examining contribution only in the introduction sections of articles.

We argue that research on interpretive case studies also needs to complement this focus on the how of the contribution with the what or content of contributions. Walsham (1995b) suggests four key generalizations that case study researchers may critically develop as key findings. While he does not explicitly link these generalizations to contributions, he is clearly concerned with contributing or how "IS case study 
researchers reflect on the basis, conduct, and reporting of their work" (p. 80). We draw on and integrate the how and what of contributions in developing our theoretical approach later in the article.

\subsection{When Is a Contribution?}

Our perspective on contribution also distinguishes the when of a contribution. In examining this, Locke and Golden-Biddle (1997) focus again solely on the construction processes: "an idea becomes a contribution, then, when it is constructed as important by the members of a scholarly community, relative to the accepted knowledge constituted by the field's written work." They do, however, suggest future research that recognizes the importance of the subsequent use of contributions. After a text is published, it travels to a variety of audiences and is used in a variety of ways (Winsor 1993). How does a text travel, relative to its construction of contribution?

Latour's (1987) work on the rhetorical construction of knowledge claims in scientific articles in the literature is instructive in this regard. As discussed later, not only does Latour offer additional positioning strategies to those of Locke and GoldenBiddle in the construction of knowledge claims, but also exhorts us to examine the later use of claims. He sums this up in his second rule of method which "asks us not to look for the intrinsic qualities of any given statement but to look instead for all the transformations it undergoes later in other hands" (p. 59). In our theoretical developments, we draw on Latour's insights concerning the use of claims to further develop the when of contribution as well as the how of contribution (through his rhetoric on positioning strategies). In so doing, we are conscious that he is primarily concerned with scientific facts and we therefore translate his work for our purposes of examining interpretive IS case studies, although we would suggest their broader applicability to interpretive case study research in general.

In the next section, we develop our theoretical approach which integrates the how, what, and when of contribution by distinguishing the construction of contributions and the use of contributions in the literature. We then discuss the research methodology followed by a case analysis of a single well-cited interpretive case study in the literature. The final section of the paper concludes by discussing and synthesizing key findings from the analysis.

\section{CONSTRUCTING AND USING CONTRIBUTIONS: A THEORETICAL APPROACH}

\subsection{Constructing Contributions in the Literature}

Table 1 summarizes the different elements of our theoretical approach concerned with how authors construct contribution. We specify four broad strategic concepts and their associated tactical approaches. The first two concepts, structuring intertextual coherence and problematizing the context for contribution, draw from Locke and Golden-Biddle's (1997) findings from their empirical grounded theory investigations of 82 articles in Administrative Science Quarterly and Academy of Management Journal. Our third concept, positioning as translating interests, draws from Latour's (1987) ideas 
on the rhetorical construction of the scientific article. He suggests that scientists move from weaker to stronger rhetoric in the construction of knowledge claims as contributions in the literature. As discussed earlier, we are conscious that there are key differences between interpretive case studies and the scientific article upon which he focuses. We carefully select specific concepts and translate them in ways that might be more appropriate to interpretive case studies. In this regard, we draw on Latour's use of soft facts ${ }^{1}$ and the process of hardening offacts, though we do not believe that his use of hard facts is appropriate for the concerns of this paper. To complement the above focus on process, the how of the contribution, implicit in the above concepts, our fourth concept develops the what or content of the contribution as four generalizations in interpretive case study research (Walsham 1995b). We now discuss each of these concepts in turn.

\subsubsection{Structuring Intertextual Coherence}

Locke and Golden-Biddle (1997) identified two processes, structuring intertextual coherence and problematizing context, which were in tension with each other. The first process, constructing intertextual coherence, refers to the need for texts to establish contribution by re-presenting and organizing "existing knowledge so as to configure a context for contribution that reflects the consen sus of previous work" (p. 1029). ${ }^{2}$ At the same time, however, and this is where the tension develops, authors must be involved in a second process of problematizing the situation. In other words, they must subvert or problematize "the very literatures that provide locations and raison d'etre for the present efforts" (p. 1029).

Locke and Golden-Biddle's (1997) analysis suggested three intertextual coherences $^{3}$ : $\quad$ synthesized coherence, progressive coherence, or non-coherence. According to Locke and Golden-Biddle, manuscripts display synthesized coherence when they "cite and draw connections between works and investigative streams not typically cited together to suggest the existence of the undeveloped research areas" (p. 103). The implication in such texts displaying synthesized coherence is that researchers working in different areas are not aware that their work points to common ideas. In contrast, progressive coherence indicates "networks of researchers linked by shared theoretical perspectives and methods working on research programs that have advanced over time" (p. 1035), highlighting cumulative knowledge growth and construction of consensus amongst researchers. Finally, in non-coherence intertextual fields, they found "referenced works that are presented as belonging to a common research program but as linked by disagreement" (p. 1038).

${ }^{1}$ Latour does not define soft facts per se, but implies that they are commonly accepted statements. Unlike hard facts, these statements are not supported by statistically significant scientific evidence (cf. p. 206).

${ }^{2}$ Latour refers to this as the context of citation.

${ }^{3}$ Locke and Golden-Biddle also identify textual acts and associated rhetorical practices with each type of coherence, but this is outside the scope of this article. 
Table 1. Key Concepts for Constructing Contributions

\begin{tabular}{|c|c|}
\hline Strategic Concept & Tactical Approach \\
\hline $\begin{array}{l}\text { Structuring Intertextual Coherence } \\
\text { (Locke and Golden-Biddle 1997) }\end{array}$ & $\begin{array}{l}\text { - Synthesized coherence } \\
\text { - Progressive coherence } \\
\text { - Non-coherence }\end{array}$ \\
\hline $\begin{array}{l}\text { Problematizing Context for Contribution } \\
\text { (Locke and Golden-Biddle 1997) }\end{array}$ & $\begin{array}{l}\text { - Incompleteness } \\
\text { - Inadequacy } \\
\text { - Incommensurability }\end{array}$ \\
\hline $\begin{array}{l}\text { Positioning as Translating Interests } \\
\text { (Latour 1987) }\end{array}$ & $\begin{array}{l}\text { - Framing for particular audiences } \\
\text { - Staging to highlight what audiences } \\
\text { should find interesting to discuss, and } \\
\text { admitting what they may find disputable } \\
\text { - Captation or subtle control of objector's } \\
\text { moves with due consideration of allowed } \\
\text { margin of negotiation of soft facts } \\
\text { - Stacking or the extension of evidence to } \\
\text { inductively support theories }\end{array}$ \\
\hline $\begin{array}{l}\text { Qualitative Generalizations as Content of } \\
\text { Contributions (Walsham 1995b) }\end{array}$ & $\begin{array}{l}\text { - Concept development } \\
\text { - Theory generation } \\
\text { - Specific implications } \\
\text { - Rich insights }\end{array}$ \\
\hline
\end{tabular}

\subsubsection{Problematizing Context for Contribution}

Three ways of problematizing an intertextual field were identified by Locke and Golden-Biddle: incompleteness, inadequacy, and incommensurability. By problematizing a literature as incomplete, the text claims that the existing literature is not finished and that the present article will further develop or specify it. A literature is problematized as inadequate when the text claims that the existing literature does not sufficiently incorporate different perspectives (relevant and important) and views to better understand the phenomena under investigation. Finally, in problematizing a text as incommensurate, an article goes further to suggest that not only does the existing literature overlook different and relevant perspectives but that the claims being made are inaccurate.

\subsubsection{Positioning as Translating Interests}

Our third concept, positioning as translating interests, draws on Latour's (1987) work, which examines the construction of scientific facts in the literature. His broad theory, sometimes referred to as the sociology of translation focuses on the process by which a knowledge claim becomes a black box (that is to say accepted as unproblematic and uncontested) or rejected. Translation consists of the ongoing process by which claims are progressively transformed as proponents seek to enrol other actors, who may accept, reject, ignore, or modify the claim depending on their own interests. In our paper, we suggest that the contribution constructed by an author is a claim to knowledge 
whose fate is always in later authors' hands. However, this does not mean that authors do not have some control in positioning their texts and protecting their stated contributions. In interpretive case studies, contributions as knowledge claims are always soft facts as distinct from hard facts, which may have more relevance in scientific articles. We draw on two ideas from Latour's work, namely, the hardening of (soft) facts and captation.

Latour discusses captation as a tactical approach in positioning strategies. He uses it to mediate the fact-builder's paradox: "how to leave someone completely free and have them at the same time completely obedient...to lay out the text so that wherever the reader is there is only one way to go" (p. 57). However, this paradox is still appropriate when translated for hardening the (soft) fact process. Latour argues that "the simplest way to spread a claim is to leave a margin of negotiation to each of the actors to transform it as he or she sees fit and to adapt it to local circumstances" (p. 208) So, a captation approach should recognize and provide a margin of negotiation in allowing later authors to translate their contribution, while simultaneously recognizing the need to retain subtle control. Control is necessary to ensure that your contribution is not lost, and still recognizable despite modification through translation by later authors. Latour goes on to note that the softer the facts the longer the networks, and the greater the potential variability in translation.

Latour suggests other positioning strategies including framing, staging, and stacking. In framing the contribution, the authors should carefully consider the audience: "In order to defend itself, the text has to explain how and by whom it should be read....If one wishes to increase the number of readers again, one has to decrease the intensity of the controversy, and reduce the resources" (p. 52). Furthermore, Latour suggests that, in aiming at a specific readership, authors should not only consider the kind of words used but also anticipate readers' objections in advance. Typical staging strategies authors should adopt are to highlight what should be discussed, what is really interesting, and that which is admittedly disputable, the latter strategy being "like taking out an insurance policy against the unexpected transformation of facts into artefacts" (p. 55). Finally, stacking strategies inductively draw on and extend evidence in supporting theories. Researchers seek to use their findings to move from a rather specific instance to suggest applicability in a more general field. Latour gives the example of a biologist who looks at small slices of flesh which are first "three hamster kidneys," then extended to be "hamster kidneys," then "rodent kidneys," and finally "mammal countercurrent structure in the kidney." In so doing, the biologist seeks to "prove as much as he can with as little as he can, considering the circumstances" (p. 51).

\subsubsection{Qualitative Generalizations}

Our fourth strategic concept is concerned with the construction of qualitative generalizations from interpretive research, which we suggest are the content of contributions. These generalizations are critical for researchers to develop and are often constructed toward the latter half of articles, in contrast to the introduction sections, which were the focus of Locke and Golden-Biddle's analysis. Four types of generalizations have been identified by Walsham (1995b): development of concepts, generation of theory, drawing of specific implications in particular domains of action, 
and contributions of rich insights which are broad insights not easily categorized as any of the other three types.

\subsection{Use of Contributions in the Literature}

As we have highlighted in the previous section, Latour emphasizes that knowledge claims or contributions are always in the hands of later authors. We drew further on his ideas in developing our theoretical approach on the use of contributions in the literature (see Table 2). We develop three elements to evaluate use of contribution along with their associated assessment criteria. The first evaluative element examines the "take up" of the content of the contributions used by later audiences. Relevant assessment criteria to consider are the nature and type of the contribution cited, and how it was related (or not) to one of the four qualitative generalizations. Another useful criterion is to examine any unusual cases of use by later texts, and to try to interpret reasons as to why specific contributions were adopted.

Our second evaluative element is the incorporation and use of contribution by later audiences. Latour argues that if (contributions as) claims to knowledge are to be effective, they must be incorporated into later statements by members of a research community. A statement (contribution) needs the next generation of papers "much like genes that cannot survive if they do not manage to pass themselves on to later bodies" (p. 38). Furthermore, Latour suggests that one needs to examine how others use and insert premises or arguments (rhetoric) from one paper into sentences of their own paper. Depending on how this modality (as he refers to it) is inserted into other sentences by others in developing their own rhetoric in papers, a given sentence becomes more of a fact or more of an artefact. Modalities, positive or negative, can further the claim positively by reinforcing the contribution or alternatively contest the claim (contribution) with negative implications for the continued life of the contribution in subsequent generations of papers. We suggest then that appropriate assessment criteria are to examine how the contributions have been incorporated and subsequently used to further other authors' claims.

A related criterion is to examine the implications of later referencing for the fate of the contribution. Latour notes a few of the many possibilities: references may be misquoted or wrong; many may have little or no bearing whatsoever on the claim and bejust for display. Other, perfunctory, citations might be present but only because they are always present in the author's articles, whatever his or her other claim, to mark affiliation to a group of researchers, and finally qualified or modalized claims (as Latour calls them), where papers may be referenced which (knowingly or not) explicitly say the contrary of the author's thesis.

Our final evaluative element concerns the success of positioning strategies. Quite simply, by evaluating how an article is referred to by later texts, the success of the framing, staging, captation, and stacking strategies can be assessed. The assessment criteria, therefore ,examine the range of audiences that authors were successful in framing, the types of staging strategies that were successful, and the extent to which captation and stacking strategies were successful. 
Table 2. Use of Contributions in the Literature

\begin{tabular}{ll}
\multicolumn{1}{c}{ Evaluative Element } & \multicolumn{1}{c}{ Assessment Criteria } \\
\hline $\begin{array}{l}\text { Content of contribution(s) used by later } \\
\text { audiences }\end{array}$ & $\begin{array}{l}\text { What was the nature and type of } \\
\text { contribution taken up and cited? }\end{array}$ \\
& $\begin{array}{l}\text { How can we account for unusual cases and } \\
\text { the take up of specific contributions? }\end{array}$ \\
\hline $\begin{array}{l}\text { Incorporation and use of contribution by } \\
\text { later audiences }\end{array}$ & $\begin{array}{l}\text { How have the contributions been } \\
\text { incorporated and used (translated) to further } \\
\text { later writer's claims? }\end{array}$ \\
& $\begin{array}{l}\text { What are the implications of later } \\
\text { referencing for the fate of the contribution? }\end{array}$ \\
\hline Success of positioning strategies & $\begin{array}{l}\text { What were the range of audiences that } \\
\text { authors were successful in framing? }\end{array}$ \\
& $\begin{array}{l}\text { What types of staging strategies were } \\
\text { successful? }\end{array}$ \\
& $\begin{array}{l}\text { To what extent were captation and stacking } \\
\text { strategies successful? }\end{array}$ \\
\hline
\end{tabular}

\section{RESEARCH METHODOLOGY}

To examine the construction and use of contribution in interpretive case study research, we had to make some difficult decisions. The first decision concerned the scope of the study, and a single interpretive case study approach was chosen. We made this decision primarily because our research design required us to carry out an in-depth study of both construction and use of contributions. Our analysis, therefore, required us not only to carefully examine all sections of the chosen interpretive case study but also to include examination of a substantial body of literature that subsequently referenced this study. The second decision concerned sample selection. Our research through the use of citation indexing software suggested that either MIS Quarterly or Information Systems Research would be suitable choices based on their number of citations. We examined a wide range of articles which used an interpretive IS case study methodology and eventually selected one that was 5 to 7 years old and was very well cited. The article selected was "Steps Toward an Ecology of Infrastructure: Design and Access for Large Information Spaces" (1996) by Susan Leigh Star and Karen Ruhleder (hereafter referred to as S\&R) in Information Systems Research. The underlying assumptions of S\&R's research are consistent with those suggested by Orlikowski and Baroudi (1991) concerning the philosophical premises ofan interpretive study, having a focus on understanding phenomena through the meanings that people assign to them. Furthermore, their use of theory (in their case, Bateson's theory) is as a sensitizing device to make sense of the world rather than the application of a positivist theory-testing approach 
(Klein and Myers 1999). As of July 2003, when our research was conducted, there were 39 citations of this paper in the literature. Of these citations, we were able to access 35.

Both authors contributed significantly to the data analysis, particularly with respect to the initial development and subsequent testing of the evaluation scheme, which required each to code the $S \& R$ paper and a number of other articles citing this paper. Specifically, we started our data analysis by separately coding all sections of S\&R using the iteratively developed theoretical framework (Table 1) for constructing contributions in the literature. We then discussed the similarities and differences in our analysis, and where we agreed we merged our findings. The data analysis for coding the use of contributions in the literature was much trickier but followed a similar process. Following open coding of a significant sample of the articles that referred to S\&R, each of the authors separately coded a subset of the articles using the evaluation and assessment criteria (Table 2). We then came together to discuss similarities and differences, and to agree on how to integrate different perspectives both in our findings and in improving our data analysis approach. The first author subsequently coded the rest of the 35 articles based on the agreed scheme and concluded the analysis.

Before discussing our findings in the next section, we present the abstract from $S \& R$ as a high level summary to aid our readers in gaining an initial broad understanding of the article.

\title{
Steps Toward an Ecology of Infrastructure: Design and Access for Large Information Spaces
}

\author{
S. Star and K. Ruhleder
}

\begin{abstract}
We analyze a large-scale custom software effort, the Worm Community System (WCS), a collaborative system designed for a geographically dispersed community of geneticists. There were complex challenges in creating this infrastructural tool, rangingfrom simple lack of resources to complex organizational and intellectual communication failures and tradeoffs. Despite high user satisfaction with the system and interface, and extensive user needs assessment, feedback, and analysis, many users experienced difficulties in signing on and use. The study was conducted during a time of unprecedented growth in the Internet and its utilities (1991-1994), and many respondents turned to the World Wide Webfor their information exchange. Using Bateson's model of levels of learning, we analyze the levels of infrastructural complexity involved in system access and designer-user communication. We analyze the connection between system development aimed at supporting specific forms of collaborative knowledge work, local organizational transformation, and large-scale infrastructural change.

(Infrastructure; Collaboratory; Organizational Computing; Participatory Design; Ethnography; Internet; Scientific Computing)
\end{abstract}




\section{THE CONSTRUCTION AND USE OF CONTRIBUTIONS IN STAR AND RUHLEDER}

Our analysis in sections 4.1 and 4.2 draws on our developed theoretical approach as summarized in Tables 1 and 2 respectively. We bold the key concepts or points in our discussion below so as to aid the reader in appreciating the connections between our discussion and the earlier theoretical approach.

\subsection{Constructing Contributions in Star and Ruhleder}

\subsubsection{Structuring Intertextual Coherence}

Contrary to a tacit implication in Locke and Golden-Biddle (1997), S\&R's article did not fall neatly into a single tactical approach or type of coherence. Nonetheless, the coherence categories were useful in identifying plural types of coherence used as tactical approaches in structuring intertextual coherence.

At the very beginning of the article, we identified patterns of synthesized coherence. In section $1, S \& R$ develop the intertextual field as being concerned with the paradoxical relationship between technology and organizational transformation. They highlight structuration theory (Giddens 1984) as an approach in analyzing this paradox but then cite connections with "web of usability and action" approaches (after Engestrom [1990] and Kling and Scacchi [1982]) to suggest the existence of undeveloped research areas. Later on, in sections 4 and 5, S\&R also adopt synthesized coherence in drawing on the above approaches; in particular, they use Bateson's ecology levels and double bind concepts to examine the logical paradox between technology and organizational transformation. Furthermore, they suggest that the added dimensions of infrastructure developed by drawing on this approach "deepens our understanding of the dual and paradoxical nature of the technology."

With respect to S\&R's treatment of the dimensions of infrastructure, this is harder to categorize. We would argue that $S \& R$ use a progressive coherence approach as they bring together the work of a range of other scholars (Bowker 1994; Jewett and Kling 1991) linked by a shared perspective on infrastructure as a relational property and who seek to build cumulative knowledge (Locke and Golden-Biddle 1997). However, it could be argued that synthesized coherence was the tactical approach used. After all, in developing infrastructure as a "fundamentally relational concept...in relation to organized practices" (p. 113), they provide an alternative approach to the common metaphors of infrastructure as a substrate or a "thing with pre-given attributes frozen in time" (p. 112). However, as discussed below, we view this more as a problematization strategy since the article does not present an intertextual field of literature per se when making this particular point.

\subsubsection{Problematizing Context for Contribution}

Intriguingly, the analysis of problematizing strategies was even more nuanced and pluralistic. The categories from Locke and Golden-Biddle (1997) once again held up 
well but, perhaps surprisingly, we identified all three forms of problematizing in this one paper. First, as highlighted at the end of the last subsection, their direct challenge of common metaphors of infrastructure as being "neither useful nor accurate in understanding the relationship between work/practice and technology" (p. 112) represents an incommensurable problematization. Second, the incompleteness problematizing approach is evident toward the end of section 1 . The authors conclude this section by emphasizing the need for more studies since they are not only important but it is "increasingly clear to us that this development effort is taking place at a moment of rare, widespread infrastructural change" (p. 114). The implication is that their study attempts to fill (or complete) this need. Finally, an inadequacy problematization is evident in section 3. In discussing CSCW typologies, the authors argue that existing approaches are inadequate "in analyzing the issues associated with implementation or integration... [nor] the relational aspects of computing infrastructure and work" (p. 116).

\subsubsection{Positioning as Translating Interests}

As structured in Table 1, our analysis identified a range of positioning strategies used by S\&R in constructing opportunities for contribution across all sections of their paper. For example, their framing strategy addressed a wide range of audiences. In section 4, they highlight the CSCW community, system development community, widely dispersed scientists, and communication researchers. In section 7, the authors signal the importance of social, information, and computer science communities in exploring the ecology of infrastructure.

A very good example of framing and staging strategies used together in the paper are illustrated in section 3 of the paper. S\&R start by framing the collaboratory infrastructure and the questions they are reporting on as being important and relevant to the CSCW community. Their subsequent staging strategies suggest an urgent need for interest and discussion as to the importance of the key arguments reflected in the paper concerning infrastructure and its relationship to work and communication: "Those working in the emergent field of CSCW, of which the collaboratory is a subset, have struggled to understand how infrastructural properties affect work, communication, and decision making" (p. 116).

Appreciating captation, or subtle control balanced with a margin of negotiation, was more challenging to ascertain within discrete parts of the paper. Pulling together various strands across the paper, we believe that captation was evident in the way the paper attempts to shift the study of information infrastructure to a study of contexts: "Information infrastructure is not a substrate which carries information on it, or in it, in a kind of mind-body dichotomy. The discontinuities are not between system and person, or technology and organization, but rather between contexts" (p. 118). In shifting the study of information infrastructure to a study of contexts, it opens the door, or provides a wide margin of negotiation in applying the concepts of information infrastructure to a number of other topics; so long (and this is where subtle control may be retained) as this is done using S\&R's theory concerning contextual levels.

Finally, S\&R employ stacking techniques to prove the value of applying Bateson's typology in examining the paradox of infrastructure. They start by examining the 
contexts of two generic processes common to any infrastructure, signing on and hooking up. They then extend this evidence to support their generated theory by discussing the "implications of this typology for other forms of system development" (p. 118). This stacking is further extended to the "broader implications for understanding the impact of new computer-based media and their integration into established communities." The last few lines of their abstract reproduced above also suggests such a strategy.

\subsubsection{Qualitative Generalizations as Content of Contributions}

As developed in Table 1, specific contributions may be manifested as one of four types of qualitative generalizations: concept development, theory generation, specific implications, and rich insights. We discuss examples of each of these in turn. First, a number of concepts are identified in S\&R. A key concept is the "when is an infrastructure," developed as a relational concept and made explicit through defined dimensions. Another example, developed from applying Bateson's double bind to infrastructural issues is the infrastructual transcontextual syndrome (ITS) concept. Second, theory generation was distinguished as the novel application of Bateson's levels of communication and related first, second, and third order issues to information infrastructure. Third, the paper also highlights a number of specific implications in addressing first, second, and third order issues. Finally, we identified rich insights on the relationships between information infrastructure technology, organizations, and communities.

\subsection{Use of Contribution in Star and Ruhleder}

\subsubsection{Content of Contribution(s) Used by Later Audiences}

Our primary focus here was to examine the nature and type of contribution cited and used by later texts. We did not try to make the contribution fit into one of the four possible qualitative generalizations but noted if it did.

The citation and use of contributions was highly diverse and somewhat surprising. In particular, the use of Bateson's model including the concept of double binds to examine the ecology of infrastructure, although central to $S \& R$ and its analysis, was rarely discussed or incorporated by later audiences. Only 4 of the 35 articles analysed made any reference to the theory or its related key concepts such as double binds (e.g., Bishop et.al. 1999; Robey and Boudreau 1999) or orders of use issues (e.g., Bishop et al. 2000). Of these, only one article (McCarthy 2000) highlights and incorporates Bateson's theory significantly in their work.

A popular type of contribution used (nine articles) was the concept of the "when of infrastructure," along with one (e.g., use of transparency by Whyte and Macintosh [2001]) of more of its eight dimensions (e.g., Borgman 2002; Jacob 2001) associated with this relational concept. Once again, this finding is interesting and somewhat unexpected. The infrastructure concept, developed early on in $S \& R$, is important for justifying the contextual approach undergirding Bateson's theory. However, it is Bateson's concepts that are central to the analysis and discussion sections of S\&R. It 
was, therefore, a little surprising that the use of the earlier infrastructure concept was significantly greater than the paper's key theory and concepts.

Unlike the above contributions, which fit the concept development qualitative generalization, the largest contribution category did not neatly fit any of the four generalizations. We refer to this category as the related work category, which accounted for just over a third of the articles surveyed. There were two different groups. First, those articles that referenced S\&R because they served as a good analogy, or early preInternet example, of related large-scale infrastructure. In these articles, specific contributions (whether theory, concepts, rich insights, or specific implications) are rarely ever discussed. One exception (DeSanctis and Monge 1999) recognizes the rich insights S\&R offer on the coupling between technology, organization structure, and communication patterns.

A second grouping of articles highlights the general proposition or broad essence of the article, without explicit reference to any of the four specific contribution types. This general proposition refers to infrastructure as a socio-technical construct, a relational concept, and recognizes the importance of its context of use. For example, Bishop et al. (2000), while not directly referencing any specific type of contribution, cite S\&R's study as being useful in examining the "context and culture of community computing in design and implementation of community services." Articles in this group recognize and adopt a "broad web of usability and action" in understanding the paradox of infrastructure. Furthermore, in two cases, the articles, in addition to citing a general proposition, also cite a specific concept, such as infrastructure as a socio-technical construct occurs when tension between local and global is resolved (Kling 2000).

The last category and smaller grouping of articles referenced specific implications or substantive concepts discussed by S\&R. For example, Min and Galle (1999), in examining e-purchasing, reference S\&R's substantive (third order issue) concept on network externalities and electronic participation which they discuss in relation to the Worm Community system.

\subsubsection{Incorporation and Use of Contribution(s) by Later Audiences}

In this subsection, we go beyond our previous examination of the nature and type of contributions. We draw on the assessment criteria in Table 2 to evaluate how contributions are referred to and incorporated by later audiences. We now discuss each of the categories which characterized our findings.

\subsubsection{Mistaken Referencing: Incorporating and Using Claims Not Discussed in the Article}

At one level, these articles can be construed to be mistaken in referencing concepts that are not discussed in the paper. For example, Ciborra and Andreu (2001) reference S\&R in connection with the concept of boundary objects. However, S\&R do not develop this concept in their article, although the concept is a well-known one developed by Star in some of her other writings. Nonetheless, in their article, Ciborra and Andreu clearly reflect the broad essence or general propositions of S\&R concerning Bateson's theoretical perspective (involving three levels/orders of use) in examining the paradox of infrastructure. Their specific case examines the use of infrastructure by a community 
involving contexts/levels and what they term interorganizational learning ladders. While this paper's specific reference to boundary objects may do little to strengthen the specific contributions made in S\&R's paper, the paper as a whole implicitly reinforces S\&R's general propositions.

\subsubsection{Ambiguous Referencing: Mixed Use of Negative and Positive Modalities}

An interesting finding was the use of ambiguous referencing. For example, Duncker (2000) references $S \& R$ in their use of the image of infrastructure as "sinking into the background." S\&R use this metaphor differently to problematize more conventional characterizations of infrastructure. Specifically, they suggest that this conceptualization "is neither useful nor accurate in understanding the relationship between work/practice and technology" (p. 112). Furthermore, this subsidiary argument in S\&R as referenced by Duncker could be wrongly interpreted by later generations of texts to be S\&R's central message. Therefore, this incorporation potentially invokes a negative modality to the claim made by S\&R as it (likely inadvertently) supports the very opposite of what their claim is trying to say, and draws attention away from the paper's more sophisticated and central claim on the ecology of infrastructure. ${ }^{4}$ In another twist of irony, Duncker goes on to expound in her notes at the end of the paper the transparency of infrastructure, which emerges when "the tension between local meaning and global standards is resolved" (p. 197). This description denotes a very good, accurate, and positively modalised claim to the S\&R original, although its chances of being reproduced in subsequent generations of papers may be similar to that of a recessive gene given its discreet location in the paper.

Another example of ambiguous referencing mentioned briefly in an earlier section concerns the use by Min and Galle in examining e-purchasing. Using the concept of network externality and electronic participation, they develop hypotheses on the number of users participating in a purchasing community. However, S\&R contrast network externality (as referring to the participation in a community) and critical mass (that focuses on the number of users). Min and Galle seem to conflate these closely related concepts in developing their hypothesis. Such ambiguous referencing could result in future translations by later audiences, which go against the intended use by S\&R. In Latour's language, future translations involving negative modalities of S\&R's original contribution may dilute or even serve to negate the contribution over time.

\subsubsection{Incorporating Statements into a New Term (Neologism)}

A number of authors incorporate S\&R's socio-technical approach into the development of a new concept or term, sometimes referred to as a neologism. For example, using Latour's terminology, Kling (2003) modalizes the claim positively to further his socio-technical integration network (STIN) model. Similarly, Kling (2000) draws on the claim as a socio-technical approach to ICT infrastructures in developing more broadly the field of social informatics in understanding IT and social change.

${ }^{4}$ In the scientific literature, Winsor (1993) identifies a similar characterization and irony with what evolutionary biologists do with adaptionist claims in their later use of a well-cited article. 


\subsubsection{Related Work Referencing}

The WCS large-scale infrastructure collaboratory, the central empirical focus of S\&R, is often cited as a good analogy for scientific research communities (Bieber et al. 2002). This and other papers (e.g., Bishop et al. 2000) use S\&R to legitimize their own research into digital libraries as an information infrastructure. Similarly, other papers cite the WCS as analogy for other large scale scientific infrastructures, such as BioDiversity infrastructures (Bowker 2000), while others (e.g., Baker et al. 2000) explicitly identify the WCS as a pioneering pre-Internet system, which has led to many other examples of networked information systems. Internet research (e.g., Valentine and Holloway 2002) draws on the use of the relational concept of infrastructure, recognizing the Internet as an information infrastructure, which emerges for people in practice, connected to activities and structures. Another type of related work referencing was evident in papers that examined the connections between classification and information infrastructure (Jacob 2001; Jacob and Shaw 1998; Palmer and Malone 2001).

\subsubsection{Success of Positioning Strategies}

This final subsection evaluates the success of positioning strategies by $S \& R$ in later texts using the assessment criteria developed in Table 2. First, we examine the range of audiences to whom $S \& R$ were successful in using framing strategies. We then assess the types of staging strategies that seem to be successful as well as to what extent captation and stacking have been successful.

Our analysis of the 35 articles citing S\&R shows that a broad set of audiences across different academic communities have cited their work and incorporated their contributions. The main audiences include researchers from information science, supply chain/e-markets, information systems, communication researchers, systems development, social informatics, and medical informatics. The majority of researchers citing S\&R were researchers in information science and social informatics, many of whom were conducting research on digital libraries. Apart from the CSCW group, which does not seem to have referenced the work to date, S\&R's framing strategies seem to have been largely successful in gaining support from a broad set of researchers in translating their key contributions.

In addition to successfully framing their work to multiple audiences, S\&R's staging of the importance of their pioneering pre-Internet work on large-scale infrastructure successfully led to significant related-work referencing. Researchers, in particular information scientists, viewed WCS as good examples/analogies that legitimated their work on digital libraries, the Internet, and other scientific large-scale infrastructures. A particularly successful positioning strategy was the incommensurable problematization of traditional representations of infrastructure and the development of a relational concept of infrastructure with its dimensions. A number of later texts cited this perspective or conceptualisation. In addition, the wide scope of dimensions (eight) of infrastructure as opposed to a more basic definition (as highlighted by Jacob 2001) provides more of what is interesting with specific dimensions being cited and translated by different authors. In line with Latour's prediction, infrastructure conceptualised as a softer fact allows longer networks and more variability in translation by later authors. 
The concept of captation is admittedly quite difficult to evaluate, although there are signs of some success by $\mathrm{S} \& \mathrm{R}$ in such strategies. For example, a number of researchers from the Information Science community have subsequently examined classification as infrastructure. This demonstrates the high margin of negotiation in translating soft facts associated with infrastructure to classification while retaining some control through the use of Bateson's theory as evidenced by it being examined as a study of contexts. For instance, the analysis by Bishop et al. (2000) of classification views it as infrastructure but examines it in a contextual study using three levels as in S\&R.

However, S\&R's stacking strategy to show the use of Bateson's typology beyond generic and widespread processes of signing on and hooking up in infrastructure to other systems development approaches has to date not been very successful in terms of take-up by others.

\section{DISCUSSION AND CONCLUSIONS}

Our study examined processes of construction and use of contributions in a wellcited interpretive case study to extend our understanding as to how such texts may better develop contributions. Our theoretical approach draws on and extends previous work on how texts construct contribution by integrating the how, what, and when of contribution. We further develop the how of contribution (Locke and Golden-Biddle 1997) by appropriating (translating) Latour's (1987) positioning strategies, which include tactics authors may use in crafting their texts. We also suggest that in constructing contribution, it is important to examine later sections of a paper beyond the introduction, and to consider how authors develop the what or content of contributions as qualitative generalizations (Walsham 1995b). Finally, drawing on Latour, we develop the when of contribution by highlighting the importance of use, and recognizing contribution as a knowledge claim whose fate depends on later texts.

In our paper, we have tailored key concepts proposed by Latour and by Locke and Golden-Biddle in elaborating a theoretical framework applicable for examining interpretive case studies. However, as hinted earlier, we recognize that elements of the framework may have wider applicability beyond interpretive studies to scientific articles (cf. Latour 1987), and further research could consider how such elements might be used in conjunction with earlier frameworks (e.g., March and Smith 1995) to examine processes of construction and use in other research approaches. We also recognize the study's current limitations concerning generalizability as our unique methodology examined a single case. However, we believe that the deeper structure of construction and use of contributions in the paper can be key learning for other researchers seeking to develop their own paper's contributions. Despite these limitations, our analysis produced a number of interesting and unexpected findings which we believe are a good first step in furthering the literature on contribution in IS interpretive case studies, as well as interpretive case study research more generally. With respect to constructing opportunities for contribution, our case confirmed the usefulness of Locke and GoldenBiddle's specific types of coherence strategies. However, we go further to suggest that texts may be successful in deploying plural strategies in constructing intertextual coherence. Our analysis also shows that texts may use all three identified problema- 
tizations across different parts of the article, an intriguing finding that Locke and Golden-Biddle's limited analysis of the introduction sections of articles could not identify.

In further examining the construction of contributions by S\&R, we drew on and translated positioning strategies from Latour's work on scientific facts to be relevant for soft facts in interpretive case studies. We also examined the content of the contributions in the S\&R study using the four qualitative generalizations provided by Walsham (1995b). While there were fewer surprises with these construction processes, in that good examples were found in each category, it did suggest the value of these extensions of previous work being incorporated in our integrated theoretical approach.

Some key findings from our analysis of the use of contributions by later texts were quite unexpected. There was little use by later texts of central theories and concepts, which from the title and content of S\&R's paper were clearly meant to be key contributions. ${ }^{5}$ Interestingly, there may be echoes here of the rigor/relevance debate (Benbasat and Zmud 1999). In S\&R, a significant level of rigor is displayed in using Bateson's more complex theoretical apparatus drawn from the communications and psychiatry community. However, the relevance as displayed by researchers in their subsequent take up seems to be lower. In contrast, the far simpler and well-crafted concept of the "when of infrastructure," clearly meant by S\&R to merely set the stage for the use of Bateson's theory later on in the paper, is surprisingly used significantly more by later authors.

A large number of citations simply recognized the study as a good example or early analogy of large-scale infrastructure and confirmed the successful framing and staging identified in S\&R. Exceptions were the deafening silence of feedback from the CSCW group (admittedly hard to identify) despite the most obvious framing and staging to this group. In addition, other groups less obviously targeted cited the work such as supply chain and purchasing, and medical informatics. This observation highlights that there are never any guarantees as to whether framing and staging strategies will be successful, and it is uncontrollable as to whom your contribution is ultimately taken up by and translated. What was also interesting was the frequency of use of the general propositions of the paper's socio-technical approach to infrastructure, which were drawn on more than specific qualitative generalizations. Furthermore, the stacking strategies used to prove the use of theory beyond common generic processes to systems development seemed to be largely unsuccessful to date.

Our findings categorize a number of different types of referencing used by later texts in incorporating and using contributions, namely mistaken referencing, ambiguous referencing, incorporating into a new term, and related- work referencing. Of particular note, ambiguous referencing took place when audiences translated concepts which involved incommensurate problematizations but with closely related meanings (e.g., critical mass and network externality).

${ }^{5}$ There are some parallels here to the findings by Mingers and Taylor (1992), which demonstrated that soft systems methodology (SSM) in practice had been used for a wide variety of tasks. Some elements of SSM were nearly always used while others were used less often. Finally, other techniques were often combined with SSM or modifications made to SSM in ways that extended well beyond the originators. 
In conclusion, we make some suggestions as to how one can construct better contributions in interpretive case studies. First, and this is a macro-level theme of the paper, be sensitive to the how, what, and when of a contribution. For example, consider carefully the use that others might make of your contributions. Second, think through your communities/target audiences and appropriate framing/staging strategies to signal to them how different contributions may be best translated by them. Third, think about your captation strategies-how to allow a high margin of negotiation by multiple audiences in translating a wide range of soft facts while attempting to retain some subtle control of the main essence of the contributions. Fourth, in constructing opportunities for contribution, do not necessarily limit yourself to a single coherence or problematization strategy. A plural strategy may very well increase the effectiveness of your contributions. Fifth, appreciate the use of incommensurate problematizations that can act as a double-edged sword. These problematizations can be a powerful staging strategy in raising significant interest and use of a contribution. However, clarity in defining concepts is critical, especially when there is significant relatedness or similarity between concepts used in the problematization. Otherwise, as we saw with the infrastructure concept or with network externality, there is the risk of possible confusion or poor translation of the contribution in future generations of texts. Sixth, try to communicate clearly the general propositions of your research in addition to developing key qualitative generalizations as our analysis suggests that this may be equally if not more important.

It can be argued that a number of the above suggestions are tacitly used by experienced researchers such as $\mathrm{S} \& \mathrm{R}$ who clearly know how to construct a contribution as evidenced by the wide citation of their article. Our paper has attempted to unearth some of the deep structures (Heracleous and Barrett 2001) of these writers and their intended strategies. However, all strategies, even of the most experienced writers, are emergent and authors cannot fully control what later users do with their projected and anticipated contributions, including this paper.

\section{REFERENCES}

Astley, W. G. "Administrative Science as Socially Constructed Truth," Administrative Science Quarterly (30), 1985, pp. 497-513.

Baker, K. S.; Benson, B. J.; Henshaw, D. L.; Blodgett, D.; Porter, J. H.; and Stafford, S. G. "Evolution of a Multisite Newtork Information System: The LTER Information Management Paradigm," Bioscience (50:11), November 2000, pp. 963-978.

Bateson, G. Steps to an Ecology of Mind, New York: Ballantine Books, 1978.

Benbasat, I., and Zmud, B. "Empirical Research in Information Systems: The Practice of Relevance," MIS Quarterly (23:1), March 1999, pp. 3-16.

Beyer, J. M.; Chanove, R. G.; and Fox, W. B. "The Review Process and the Fates of Manuscripts Submitted to AMJ," Academy of Management Journal (38), 1995, pp. 1219-1260.

Bieber, M.; Engelbart, D.; Furuta, R.; Hiltz, S. R.; Noll, J.; Preece, J.; Stohr, E. A.; Turoff, M.; and Van de Walle, B. "Toward Virtual Community Knowledge Evolution," Journal of Management Information Systems (18:4), 2002, pp. 11-35.

Bishop, A. P.; Neumann, L. J.; Star, S. L.; Merkel, C.; Ignacio, E.; and Sandusky, R. J. "Digital Libraries: Situating Use in Changing Information Infrastructure," Journal of The American Society for Information Science (51:4), 2000, pp. 394-413. 
Bishop, A. P.; Tidline, T. J.; Shoemaker, S.; and Salela, P. "Public Libraries and Networked Information Services in Low-Income Communities," Library \& Information Science Research (21:3), 1999, pp. 361-390.

Borgman, C. L. "Challenges in Building Digital Libraries for the $21^{\text {st }}$ Century," in E-P. Lim, S. Foo, and C. Khoo (Eds.), Digital Libraries: People, Knowledge \& Technology: Proceedings of the $5^{\text {th }}$ International Conference on Asian Digital Libraries (ICADL 2002), Heidelberg: Springer-Verlag, 2002, pp. 1-13

Bowker, G. "Biodiversity Datadiversity," Social Studies ofScience (30:5), October 2000, pp. 643-683.

Bowker, G. "Information Mythology and Infrastructure," in L. Bud-Frierman (Ed.), Information Acumen: The Understanding and Use of Knowledge in Modern Business, London: Routledge, 1994, pp. 231-247.

Ciborra, C. U., and Andreu, R. "Sharing Knowledge Across Boundaries," Journal of Information Technology (16), 2001, pp. 73-81.

Davenport, T., and Markus, L. " Rigor vs. Relevance Revisited: Response to Benbasat and Zmud," MIS Quarterly (23:1), March 1999, pp. 19-23.

DeSanctis, G., and Monge, P. "Introduction to the Special Issue: Communication Processes for Virtual Organizations," Organization Science (10:6), November-December 1999, pp. 693703.

Duncker, E. "How LINCs Were Made: Alignment and Exclusion in American Medical Informatics," The Information Society (16), 2000, pp. 187-199.

Engestrom, Y. "When is a Tool? Multiple Meanings of Artifacts in Human Activity," in Learning, Working and Imagining, Helsinki: Orienta-Konsultit Oy, 1990.

Giddens, A. The Constitution of Society, Cambridge: Polity Press, 1984.

Heracleous, L., and Barrett, M. "Organizational Change as Discourse: Communicative Actions and Deep Structures in the Context of IT Implementation," Academy of Management Journal, (44:4), 2001, pp. 755-778.

Jacob, E. K. "The Everyday World of Work: Two Approaches to the Investigation of Classification in Context," Journal of Documentation (57:1), January 2001, pp. 76-99.

Jacob, E. K., and Shaw, D. "Sociocognitive Perpsectives on Representation," Annual Review of Information Science and Technology (33), 1998, pp. 131-185.

Jewett, T., and Kling, R. "The Dynamics ofComputerization in a Social Science Research Team: A Case Study of Infrastructure, Strategies, and Skills," Social Science Computer Review (9), 1991, pp. 246-275.

Klein, H. K., and Myers, M. D. "A Set of Principles for Conducting and Evaluating Interpretive Field Studies in Information Systems," MIS Quarterly (23:1), 1999, pp. 67-94.

Kling, R. "A Bit More to It: Scholarly Communication Forums as Socio-Technical Interaction Networks," Journal of the American Society for Information Science and Technology (54:1), 2003, pp. 47-67.

Kling, R. "Learning About Information Technologies and Social Change: The Contribution of Social Informatics," The Information Society (16), 2000, pp. 217-232.

Kling, R., and Scacchi, W. "The Web of Computing: Computing Technology as Social Organization," Advances in Computers (21), 1982, pp. 3-78.

Knorr-Cetina, K. The Manufacture of Knowledge: An Essay on the Constructivist and Contextual Nature ofScience, New York: Pergamon Press, 1981.

Latour, B. Science in Action, Cambridge, MA: Harvard University Press, 1987.

Locke, K., and Golden-Biddle, K. "Constructing Opportunities for Contribution: Structuring Intertextual Coherence and 'Problematizing' in Organizational Studies," Academy of Management Journal (40:5), 1997, pp. 1023-1062.

March, S. T., and Smith, G. F. "Design and Natural Science Research on Information Technology," Decision Support Systems (15), 1995, pp. 251-266. 
McCarthy, J. "The Paradox of Understanding Work for Design," International Journal HumanComputer Studies (53), 2000, pp. 197-219.

Min, H., and Galle, W. P. "Electronic Commerce Usage in Business-to-Business Purchasing," International Journal of Operations \& Production Management (19:9), 1999, pp. 909-921.

Mingers, J., and Taylor, S. "The Use of Soft Systems Methodology in Practice," Journal of Operational Research Society (43:4), 1992, pp. 321-332.

Mone, M. A., and McKinley, W. "The Uniqueness Value and its Consequences for Organization Studies," Journal of Management Inquiry (2), 1993, pp. 284-296.

Orlikowski, W. J., and Baroudi, J. J. "Studying Information Technology in Organizations: Research Approaches and Assumptions," Information Systems Research (2:1), 1991, pp. 1 -28.

Palmer, C. L., and Malone, C. K. "Elaborate Isolation: Metastructures of Knowledge About Women," The Information Society (17), 2001, pp. 179-194.

Robey, D., and Boudreau, M. "Accounting for the Contradictory Organizational Consequences of Information Technology: Theoretical Directions and Methodological Implications," Information Systems Research (10:2), 1999, pp. 167-185.

Star, S. L., and Ruhleder, K. "Steps Toward an Ecology of Infrastructure: Design and Access for Large Information Spaces," Information Systems Research (7:1), 1996, pp. 111-134.

Valentine, G., and Holloway, S. L. "Cyberkids? Exploring Children's Identities and Social Networks in On-Line and Off-Line Worlds," Annals of the Association of American Geographers (92:2), 2002, pp. 302-319.

Walsham, G. "The Emergence of Interpretivism in IS Research," Information Systems Research (6:4), 1995(a), pp. 376-394.

Walsham, G. "Interpretive Case Studies in IS Research: Nature and Method," European Journal of Information Systems (4), 1995(b), pp. 74-81.

Webster, J., and Watson, R. T. "Analyzing the Past to Prepare for the Future: Writing a Literature Review, MIS Quarterly (26:2), June 2002, pp. xiii-xxiii

Weick, K. E. "Editing Innovation into Administrative Science Quarterly," in L .L. Cummings and P. J. Frost (Eds.), Publishing in the Organizational Sciences, Thousand Oaks, CA: Sage Publications, 1995, pp. 284-296.

Whetten, D. A. “What Constitutes a Theoretical Contribution?" Academy of Management Review (14), 1989, pp. 490-495.

Whyte, A., and Macintosh, A. "Transparency and Teledemocracy: Issues from an 'Econsultation'," Journal of Information Science (27:4), 2001, pp. 187-198.

Winsor, D. A. "Constructing Scientific Knowledge in Gould and Lewontin's 'The Spandrels of San Marco,", in J. Selzer (Ed.), Understanding Scientific Prose, Madison: University of Wisconsin Press, 1993, pp. 127-143.

\section{ABOUT THE AUTHORS}

Michael Barrett is a senior lecturer in Information Systems and E-Business at the Judge Institute of Management, University of Cambridge, where he also earned his Ph.D. His current research is principally concerned with processes of innovation, change, and use of information and communication technologies in the context of globalization, and the consequences for the nature of work. His work has been published in a wide range of management journals including Information Systems Research, Academy of Management Journal, and European Journal of Information Systems.

Geoff Walsham is a professor of Management Studies at the Judge Institute of Management, Cambridge University, UK. His teaching and research is centered on the social and management aspects of the design and use of information and communication technologies, in the context of both industrialized and developing countries. His publications include Interpreting Information Systems in Organizations (Wiley 1993), and Making a World of Difference: IT in a Global Context (Wiley, 2001). He can be reached at g.walsham@jims.cam.ac.uk. 